\title{
Los recursos humorísticos en las columnas de Alfonso Ussía sobre la política vasca
}

\section{Humours Techniques in Alfonso Ussia's Columns on Basque Politics}

\section{David Herrera Cerezo. Universidad CEU San Pablo}

\section{Resumen:}

El objeto del presente estudio es analizar los recursos que definen el estilo humorístico de Alfonso Ussía a través de algunas de las columnas sobre la política vasca que ha publicado durante sus más de treinta años de carrera periodística. Se trata de un trabajo puramente descriptivo en el que se abordan ocho de las técnicas que el autor emplea con más frecuencia para ridiculizar las ansias nacionalistas de ciertos políticos o criticar con dureza el sinsentido y la barbarie de la banda terrorista ETA. Mediante este estilo Ussía ha logrado crearse un ethos marcado por una absoluta intransigencia ante dichos planteamientos y un ferviente apoyo a las víctimas del terrorismo.

Palabras clave:

Alfonso Ussía, Columna de opinión, Columna de humor, Nacionalismo vasco, terrorismo, ethos Abstract:

The aim of the present study is to analyse the different resources defining Alfonso Ussia's humorous style through some of the columns on Basque politics that he has published during his more than 30 years of journalistic career. It is a strictly descriptive study in which we tackle eight of the techniques that the author uses more often in order to deride certain politicians' nationalistic aspirations and fiercely criticise the terrorist group ETA's pointlessness and brutality. Through this style Ussia has developed an ethos which is marked by his total rejection of these ideas and his passionate support for the victims of terrorism.

Key Words:

Alfonso Ussía, Opinion column, Humour column, Basque nationalism, terrorism, ethos 


\section{Introducción}

En el presente trabajo se analiza el estilo de uno de los máximos representantes del columnismo de nuestros días y uno de los pocos que ha ejercido la profesión ininterrumpidamente desde hace más de treinta años: Alfonso Ussía. El autor madrileño se ha convertido en un testigo excepcional de la historia más reciente de España y su nombre se encuentra entre la nómina de firmas más representativas del columnismo de humor de nuestro días.

A lo largo de su carrera periodística Ussía ha puesto en el punto de mira de su burla y su ironía a presidentes, ministros, diputados, periodistas, futbolistas, cantantes, actores, toreros, etcétera. Pero, de entre todos ellos, cabe subrayar la especial predilección que ha mostrado por aquellos personajes de la actualidad que guardan, directa o indirectamente, alguna relación con la política del País Vasco.

Dada la relevancia que este tema cobra en el corpus de la obra de Ussía, en el presente trabajo abordaremos la aplicación de los recursos de humor precisamente en aquellas columnas que versen sobre cuestiones relacionadas con la política vasca, como el nacionalismo o el terrorismo de la banda terrorista ETA.

Hasta la fecha no se ha publicado trabajo alguno que analice en profundidad el estilo de Alfonso Ussía, motivo por el cual se presenta la oportunidad de abrir un nuevo campo de estudio sin explorar todavía. Se trata de un trabajo puramente descriptivo en el que se analizan ocho de las técnicas de humor que más frecuentemente emplea Ussía para desarrollar sus argumentos sobre la política vasca. Se mostrarán ejemplos de cada uno de estos recursos que han sido extraídos del corpus de la obra periodística del autor.

\section{La columna como género periodístico}

La configuración actual de la columna de opinión surge como el resultado de la confluencia de diversos géneros, tanto periodísticos como literarios, a lo largo de varios siglos. De ahí que no exista una absoluta unanimidad entre los investigadores al clasificar el género como un tipo de escrito intrínseco a la profesión periodística o como un paso más dentro de la propia evolución de la literatura. La libertad de que disfruta el autor para plasmar sus pensamientos representa quizá el único rasgo unificador de todo el espectro de columnas que se publican actualmente en los medios impresos. López Pan constata dicha circunstancia al definir el género como "un texto periodístico de autoría individual que aparece con asiduidad en un mismo medio y que se caracteriza por su alto grado de libertad en cuanto a temas, ideas, estilo, tono, estructura y formas expresivas" (2008: 60). Y es que, efectivamente, los columnistas encuentran en el género una oportunidad única para abordar una amplia variedad de cuestiones, generalmente relacionadas con la 
actualidad del día, pero desde una perspectiva más amena y distendida que en otros géneros más sobrios del periódico. Gracias a esta libertad, la columna de opinión da la bienvenida a un extraordinario elenco de recursos y juegos estilísticos propios de las mejores obras literarias y que constituyen el alma de un tipo de escrito en el que predomina, ante todo, el virtuosismo y el dinamismo. En este sentido, apunta López Hidalgo:

"El lenguaje del columnista busca la belleza en ese difícil equilibro entre periodismo y literatura, por eso a veces es lírico y metafórico, y otras sarcástico y grosero, y sobre todo desgarrado, porque el columnista expone su opinión ante la realidad, pero sobre todo expresa su estado de ánimo" (1996: 135).

López Hidalgo hace también referencia a uno de los puntos más significativos que determinan el estilo del género. El columnista se apoya en ese amplio margen de maniobra de que disfruta para dar a conocer al lector su propia personalidad -o la que a él le interesa trasmitir-, lo cual, a su vez, le sirve en mucha ocasiones como coartada para reforzar sus propias opiniones. Sirva como ejemplo el siguiente extracto de una columna del propio Ussía en la que da a conocer al lector una infinidad de detalles de su vida privada y su arraigo con el País Vasco. Mediante esta información, el autor pretende, por una parte, estrechar su relación con el lector al hacerle confidente de algunas cuestiones personales y, por otra, demostrar su amplio conocimiento de la realidad en el País Vasco. De esta manera, crea un argumento de un inconmensurable valor emocional -sus vivencias y recuerdos de la infancia en dicha comunidad- para así poder justificar sus futuras posiciones referentes al nacionalismo o al terrorismo:

“Mi padre es vasco. [...] El amor a lo vasco por parte de mi padre es natural. Mi madre se enamoró desde niña,
porque Pedro Muñoz-Seca, su padre, pasaba tres meses cada año en San Sebastián. Incluso estuvo a punto de
comprar una villa en Ondarreta. [...] Mis hermanos y yo aprendimos a rezar simultáneamente en español y en
vascuence. [...] Cuando falleció mi madre, en su funeral, se cantó en el idioma de los vascos. Y cantamos el 'Gure
Aitá', el Padrenuestro en vascuence. Y al final, el 'Agur Jesusen Ama', que es la culminación popular de la 'Salve'
de Santa María que canta el Orfeón Donostiarra en la víspera del Día de la Virgen de agosto” (2004a). Gracias a esta última circunstancia, y a la estricta rigidez formal del género -la columna tiene una extensión y una periodicidad fijas, así como un lugar diferenciador dentro del periódico-, se produce una especie de "relación" entre el columnista y el lector. El primero sabe para quién está escribiendo, pues generalmente los lectores suelen acudir a aquellos autores cuyo pensamiento ideológico sea similar al suyo y así poder reafirmarse en sus convencimientos. Investigadores y columnistas, como Antonio Muñoz Molina, alertan precisamente de esta tendencia: "El lector perezoso y sectario es alimentado por el columnista en su pereza y su sectarismo, y le pide a cambio no que le deslumbre o que le desafíe, 
sino tan sólo que le confirme en sus prejuicios" (2007: 8-9). Pero, de una forma paralela, el lector también sabe que tiene una cita con su autor preferido ciertos días de la semana y en el mismo lugar de encuentro y, además, conoce de antemano su tendencia, su forma de entender la vida e incluso algunos datos personales que el columnista ya se ha preocupado en darle a conocer previamente. Esta imagen que el autor ha sabido construirse gracias a la libertad de contenidos del género entronca directamente con lo que la Retórica clásica denominaba ethos. En este sentido, López Pan piensa que "de entre todos los lectores, solo se convierte en audiencia de un columnista aquel lector que lo lee porque sintoniza con el ethos, el talante, el yo implícito en la columna" (2008: 63). Otros autores como Alexis Grohmann aceptan la existencia de ese ethos, pero consideran que no se trata sino de una "máscara" del propio autor: "El 'yo' de la columna es su narrador y por lo tanto no debe confundirse nunca con su autor" (2006: 35).

La extraordinaria libertad en los contenidos, la constante búsqueda de la amenidad y el atractivo, y el empeño del columnista por "enganchar" al lector a través de sus argumentos y, sobre todo, de la forma de presentarlos, abren las puertas a una de los técnicas más representativas del columnismo de nuestros días: los recursos de humor. Muchos de los más prolijos autores de este género hacen de la ironía, la sátira o el chiste la columna vertebral sobre la que fundamentan su argumentación, recogiendo así el legado de una técnica tan íntimamente arraigada a la historia del periodismo español. No en vano, el articulismo satírico y humorístico representa, sin duda, una de las mayores joyas de la literatura y el periodismo de nuestro país. Y como hemos adelantado previamente, Alfonso Ussía se encuentra, sin duda, dentro de la nómina de los columnistas de nuestros días que manejan estas técnicas con un mayor virtuosismo.

\section{Dos antecedentes: Larra y Fernández Flórez}

Antes de adentrarnos en la obra de Ussía, deslizaremos unas pinceladas acerca de dos de los grandes maestros del género, sin los cuales no podría concebirse el estilo del columnista en la actualidad. Así, la primera referencia casi obligada de la historia del columnismo debe centrarse en la figura de Mariano José de Larra. Pocos hicieron un uso de la sátira en los comentarios sobre costumbres, política o cultura como él y, dos siglos después de su nacimiento, columnistas de nuestro tiempo, como Vicente Molina Foix, aún siguen viendo en el periodista madrileño una referencia a la que seguir: "Larra sigue siendo un modelo de valentía y lucidez; yo lo releo a menudo, y trato de seguir sus pasos en la independencia y la claridad” (2006). En este sentido, Fabiola Morales señala las tres características de la obra de Larra que, en su opinión, entroncan directamente con el estilo del columnismo de nuestros días: "La prevalencia de la firma del autor, así 
como la instrumentalización de los recursos humorísticos para fines más pragmáticos que estéticos, y la preocupación por el público" (1999: 52).

Otra de las figuras representativas de la historia del periodismo de humor en España fue, sin duda, Wenceslao Fernández Flórez. Miembro de la Real Academia Española desde 1945, el periodista coruñés dispuso de una agudeza única para dotar de una extraordinaria carga humorística e irónica a sus comentarios y críticas sobre la actualidad informativa de entonces. De esta manera el propio autor hacía referencia en su discurso de ingreso académico a la importancia del sentido del humor en el análisis de los acontecimientos históricos:

"Cuando el humor se debilita o desaparece pasa una sombra sobre la vida de los pueblos, porque es él quien la interpreta y la corrige con más afable simpatía, y quien nos sugiere las visiones con que encubrimos su fealdad, y hasta quien nos presta la sonrisa con que afrontamos muchos dolores inevitables" (1945: 28).

\section{El columnismo de humor}

Según Forneas, el columnista persigue dos objetivos cuando emplea un estilo humorístico: "Poner de relieve aquello que según nuestro punto de vista se considera vicioso, mediante la ridiculización, y de esta manera desacreditarlo y, por otro, evadir una posible censura mediante la alusión y el doble sentido" (2003: 154). Además, Forneas añade: "Se busca la simpatía del público hacia el discurso mediante el humor que está emparentado con el ethos (grado moderado de emoción), aunque distinto de él, es decir, con los afectos suaves" (2003: 154).

Efectivamente, según apunta Forneas, conviene subrayar que este tipo de recursos le brindan al columnista unas extraordinarias posibilidades de expresión para así poder esquivar la censura. No obstante, el momento histórico obviamente resulta decisivo para que el margen de maniobra en los contenidos sea mayor o menor. Al menos ese es el argumento que Rafael Mainar le encontraba en el año 1906 al languidecimiento que, en su opinión, se estaba produciendo entonces del periódico satírico: "La libertad de prensa es lo bastante amplia para que el periodista no haya de pasarse la vida estrujando el ingenio para decir lo que ingeniosa y veladamente puede decirse, porque va siendo muy poco lo que no se ha dicho o no se pueda decir claro y neto" (2005: 182). Si bien hoy día disfrutamos de una extraordinaria libertad de expresión, recogida en el artículo 20 de la Constitución, el Código Penal protege a los ciudadanos de cara a los insultos y ridiculizaciones que puedan verterse en los medios de comunicación y diferencia claramente entre delitos por injurias o calumnias, en función de la gravedad de las palabras. Y es ahí donde el empleo de recursos de humor juega un importante rol, pues el columnista en muchas ocasiones puede agarrarse a la literalidad 
del chiste o la ironía y así esquivar una querella del personaje que haya sido objeto de su burla. No obstante, como veremos más adelante, este tipo de recursos estilísticos no han sido óbice para que algunos representantes del nacionalismo se hayan querellado en diversas ocasiones contra Alfonso Ussía como consecuencia de algún comentario jocoso acerca de ellos.

Con estas líneas estamos, en definitiva, ya avanzando la afinadísima y desgarradísima crítica que se esconde tras la inofensiva apariencia de las técnicas humorísticas que se emplean en el columnismo de opinión. Para entender esa poderosa intencionalidad resulta fundamental analizar los elementos que intervienen en el proceso comunicativo de estos recursos y cómo su configuración adquiere una relevancia máxima para que el entendimiento del chiste resulte exitoso. Así, Morales considera que son cinco los elementos que vertebran el proceso comunicativo de las columnas humorísticas: el emisor, el receptor, el contenido aparente, el contenido real y la clave de atención (1999: 69). Fernández Flórez hace gala de su clásico tono burlón y en el discurso anteriormente citado define el periodismo de humor mediante un esquema similar, pero con una comparación un tanto más cómica: "una casita de caramelo donde vivía un ogro de un cuento de niños" (1945: 9). La correcta activación de la clave de atención, es decir, el entendimiento y posterior aceptación del recurso humorístico empleado por el autor, será fundamental para que el lector descifre correctamente el contenido aparente (la casita de caramelo) y pueda comprender el mensaje real que el columnista desea trasmitir y que se encuentra escondido (el ogro). Para que este proceso resulte exitoso resulta imprescindible que entre el columnista y el lector exista un punto común de entendimiento y que ambos compartan los mismos códigos de análisis e interpretación de la realidad. Y precisamente la presencia de los recursos de humor en el columnismo viene relacionada con algunas de las cuestiones inherentes al propio género que analizábamos previamente y que determinan esa estrecha relación que existe entre el lector y el autor. En otras palabras, no podríamos concebir el éxito de un comentario sarcástico y jocoso si no existiese previamente esa relación tan estrecha entre el columnista y el lector o si este no acudiese a aquel autor que le brinda unas opiniones afines a las suyas.

Por ello, según DeWeese, pueden producirse tres situaciones cuando un autor emite un comentario irónico, en función del grado de entendimiento y compenetración que exista entre este y el lector: "Si está de acuerdo con el autor, la lectura será grata, incluso divertida. Si no, el efecto será diferente, quizás porque se vea obligado a justificar más sus opiniones ante el ataque hecho en la narración. Y si no la percibe en absoluto, pues, éste es otro problema" (2003: 41). Fernández Flórez explica, a través de su particular metáfora, qué puede ocurrir cuando el lector se topa con un recurso de humor: 
"Los unos saborean lo exterior, las paredes, e ignoran al ogro; los otros conocen al ogro y le desdeñan por sus paredes. Los primeros los que, después de leer las páginas de un humorista, le felicitan protectoramente con unas palmaditas en los hombros, asegurándole que 'aquella cosita que conocen de él les ha hecho pasar un buen rato' [...] Los segundos son los que braman que los asuntos serios no han de ser tratados sino con seriedad" (1945: 9).

\section{Perfil biográfico de Alfonso Ussía}

Alfonso Ussía nació en Madrid en 1948 en el seno de una familia con gran arraigo literario; su abuelo, como señalamos previamente, era el dramaturgo Pedro Muñoz-Seca. Comenzó los estudios de Periodismo y Derecho, pero no concluyó ninguna de las dos licenciaturas. Además de su prolija labor como columnista, cabe destacar su participación como comentarista en diferentes programas radiofónicos, fundamentalmente en la Cadena Cope y Onda Cero, e incluso algunas incursiones en televisión como su participación a mediados de los noventa en Este país necesita un repaso, adaptación de la tertulia satírica del programa radiofónico Protagonistas de Luis del Olmo que se emitía en Tele 5. Ha publicado varias antologías de su obra periodística, como El bosque sonriente, El temblor diario, Patriotas adosados (obra que recoge diversas columnas de Ussía sobre el País Vasco y viñetas de Mingote sobre el tema) o Resentidos, torpes y traidores. Además, es el creador de un simpático y peculiar personaje, el marqués de Sotoancho, sobre el que ha escrito varios libros como Pachucha tirando a mal, Un talibán en La Jaralera o ¡Milagro! se ha muerto mamá, entre otros. De los galardones que ha recibido como fruto de su obra periodística destacan los premios Mariano de Cavia y González Ruano.

Su primera publicación en sentido estricto data del año 1970. En aquel año la revista Litoral publicó un número especial titulado "Nueva Generación” (1970) compuesto por una serie de poemas de las promesas de la literatura española del momento. Así, además de Ussía, aquella edición contó con la colaboración de jóvenes firmas de la talla de Goytisolo, Muñoz Molina o Molina Foix. Siete años después, en 1977, el autor dio sus primeros pasos como comentarista de la actualidad en Sábado Gráfico, semanario satírico en el que publicaba una serie de versos humorísticos dentro de una sección que se llamaba El cocodrilo Leopoldo y en el que colaboró hasta diciembre de 1982. En esta revista recibió las primeras amenazas de su carrera a raíz de unos versos publicados en 1979, y reproducidos por el propio Ussía en una columna años después, en los que ironizaba sobre la nacionalidad de Telesforo Monzón, un militante nacionalista, primero del PNV y posteriormente de HB: "Pero tenga más decoro/ y piense un poco, primero: / ¿Cómo va a ser extranjero / llamándose Telesforo?” (1985a). Este tipo de versos satíricos estarán muy presentes a lo largo de toda su carrera como columnista. 
Durante los últimos meses de su periplo en Sábado Gráfico, Ussía compaginó dicha actividad con una colaboración en el diario Ya. En este periódico ejerció como analista parlamentario, mediante un tipo de crónicas de ambiente con un cierto toque humorístico en las que entremezclaba el comentario y la poesía. Seguidamente, en 1983, pasó a colaborar en Diario 16 y en Las Provincias. Del diario valenciano queremos rescatar dos extractos atípicos de su obra en los que nos encontramos con un Ussía indignado e impotente ante la situación del País Vasco. En el primero renuncia públicamente a volver a escribir una sola palabra sobre el tema -una promesa que evidentemente incumplió- como consecuencia de unas declaraciones del entonces lehendakari Carlos Garaicoechea:

"Hoy, prometo a mis lectores que es la última vez que me ocupo de ellos, que me desangro por ellos, que por ellos me conmociono. [...] Que ni una sola duda quede en estas líneas de lo que pienso. [...] Es la última vez que escribo sobre mi tierra. Y siento, no sé por qué, una acentuadísima vergüenza” (1983).

En la segunda insinúa incluso que, debido a la gravedad de la situación política y del apoyo popular que había recibido una manifestación a favor de la negociación política con ETA, la solución podría pasar por la independencia del País Vasco:

“Nunca pensé que llegaría el día, maldito día, que renunciara a mi vieja y querida patria vasca, la cuna paterna de los míos. Contra los terroristas se podía luchar, pero no contra el veneno cerril de todo un pueblo. Renuncio a defenderla y abdico de amarla. No perdamos más el tiempo ni más vidas inocentes por mantenerla en nuestra esperanza de españoles libres. Que levanten el ancla y zarpen definitivamente. Que se hundan solos con sus miserias. Que se separen para siempre" (1986).

En abril de 1984 Alfonso Ussía inició su relación con el diario $A b c$. Previamente a su extensa y dilatada obra como columnista en las páginas de opinión de este periódico, el autor comenzó a colaborar en Los Domingos de Abc con unos versos semanales de carácter satírico. En 1988 emprendió una nueva andadura en el suplemento dominical de este diario, con la publicación de una serie de artículos sobre los modales, las "buenas formas" y el protocolo, bañadas de una agudísima sátira y un gran sentido del humor, que conformarían el embrión de la trilogía los Tratados de las buenas maneras. Entretanto también tuvo tiempo para dirigir entre octubre de 1984 y enero de 1985 dieciséis números del semanario satírico y de humor El Cocodrilo.

La burla de los comentarios de Ussía ha traído consigo diversas querellas interpuestas por sus "víctimas" a lo largo de toda su carrera. Una de ellas se produjo precisamente en el diario $A b c$ como consecuencia de un texto en el que ironizaba sobre la traducción en castellano del apellido del concejal de HB en el Ayuntamiento de Bilbao, Josu Barandika: “Escrupulosamente traducido, Barandica significa “endrinal”. [...] Así que 
don Jesús Barandica, concejal del Ayuntamiento de Bilbao, es un conjunto de ciruelos, cosa que está muy bien y no merece animadversiones, pero además de un conjunto de ciruelos, Barandica es un pobre bestia" (1991). La relación de Ussía con Abc concluyó tras la negativa por parte del periódico a publicar una columna en la que el autor ironizaba acerca del cerdo de raza vasca, a raíz de la publicación en el Boletín Oficial del País Vasco (BOPV) de la reglamentación específica de dicha variante porcina. Este texto vio la luz finalmente en el diario La Razón, diario en el que colabora desde entonces.

\section{Recursos de humor en la obra de Ussía}

Ya se ha podido apreciar en estos primeros ejemplos la agudeza del lenguaje burlón y sarcástico de Alfonso Ussía y su firme posición respecto a ciertas cuestiones de la política vasca. Se ha entrevisto, en definitiva, el absoluto rechazo que muestra frente a los planteamientos nacionalistas. Y es que Ussía siempre se ha mostrado como un férreo defensor de la unidad de España, de la Monarquía española y concretamente de la figura de don Juan de Borbón. Especial relevancia tienen en su obra, por ello, todos los temas relacionados con el País Vasco y con la banda terrorista ETA.

Como consecuencia de esa implacable defensa que profesa de la unidad de España, según veremos a continuación, el autor muestra su más absoluto apoyo o su más radical rechazo a los diferentes protagonistas de la actualidad, en función del grado de apego de estos con las tesis nacionalistas. Y para conseguir una mayor adhesión del lector a sus tesis, Ussía ha hecho de los recursos humorísticos uno de los bastiones de referencia de su obra.

Cabe apuntar que para poder entender la obra de Ussía, y muchos de sus recursos humorísticos, hay que tener también en cuenta la imagen elitista y aristocrática que le gusta transmitir a través de sus escritos. Él deja entrever en muchas ocasiones estos rasgos de su forma de ser y, como veremos, los utiliza como un arma para desacreditar y ridiculizar a los representantes del nacionalismo vasco. Veamos en este extracto cómo se definía a sí mismo el propio Ussía ya a mediados de los años ochenta:

“Sencillo y simpático’ es quizá la definición que más certeramente se acerca a mis características. Si en ocasiones parezco un tanto estirado es por razones de timidez que, una vez superada, se convierte en elegante y aristocrática campechanía. 'Es el más simpático de los Ussía' era frase que se escuchaba con insistencia en el barrio de Salamanca” (1985b).

A continuación expondremos las técnicas más representativas del estilo de Ussía, agrupadas dentro de ocho categorías diferentes. Como se podrá comprobar, en ocasiones la línea que divide un tipo de recurso de 
otro es tan fina que habrá algunos aspectos englobados dentro de una técnica que guardan una gran semejanza con otra.

\subsection{La ironía}

La ironía es el recurso humorístico por excelencia en la obra periodística de Alfonso Ussía. Desde sus primeros pasos como comentarista en Sábado Gráfico hasta nuestros días, muchas de sus columnas, incluso aquellas con un estilo más frío y sobrio, han estado marcadas por una fuerte carga irónica. Álex Grijelmo define este recurso como una figura retórica que consiste "en dar a entender los contrario de lo que se dice, pero de modo que se dice mucho más de lo que se dice, muchísimo más que si se dijera exactamente lo que se quiere decir" (2003: 310). Por ello, resulta fundamental que el autor sepa emplear este recurso con un afinadísimo cuidado. De lo contrario, si el lector no sabe captar el verdadero mensaje que el columnista pretende transmitir, la ironía puede quedar vacía de contenido. Turpin apunta: "Sería algo así como querer explicar el sentido de una gracia o chiste a quien no lo ha entendido a la primera, algo muy decepcionante, pues decepciona la ausencia de respuesta esperada" (2003: 114).

El fin último de esta práctica es criticar y ridiculizar a todo aquel que, en opinión de Ussía, apoya directa o indirectamente las tesis del nacionalismo vasco, así como ensalzar a los que no lo hacen. De ahí que el autor juegue con el grado de burla en función del apego del personaje en cuestión con las ideas nacionalistas. Muestra de ello son estas palabras de ridiculización hacia las declaraciones de una representante de Eusko Alkartasuna en las que defendía la existencia de varias naciones dentro de España: "El Rey es un despistado de campeonato. La Casa Real tiene la obligación de contratar a doñapuris para guiar al Rey en el aprendizaje del nuevo descubrimiento. La nación de naciones. En efecto, el Rey no se ha enterado todavía. Ni yo" (2004c).

En muchas ocasiones, Ussía adopta una posición de ignorancia e inocencia pueril para así expresar abiertamente su parecer acerca de los acontecimientos. Sirva como ejemplo este extracto en el que reprocha la posición adoptada por el PNV ante unas maniobras desarrolladas por el Ejército en el País Vasco: "Los del PNV se enfadan últimamente por cosas rarísimas. Se enfadan tanto que formulan preguntas razonablemente cretinas en el Congreso de los Diputados. No les han explicado bien la Historia ni la Geografía. Han tenido profesores muy poco aplicados" (2009b).

\subsection{El sarcasmo}

La Real Academia Española define el sarcasmo como una "burla sangrienta, ironía mordaz y cruel con que se ofende o maltrata a alguien o algo" (1992). Según esta definición, podemos afirmar que la ironía se "con- 
vierte" en sarcasmo cuando tras su contenido aparente se esconde una crítica hiriente y cruel. En la práctica a veces resulta complicado establecer esa fina línea que separa ambos recursos. Más aún si tenemos en cuenta la dureza y la ofensa que se pueden hallar tras la mayoría de los comentarios irónicos de Ussía acerca del nacionalismo vasco o, sobre todo, del terrorismo. En el siguiente ejemplo no cabe duda, sin embargo, de la extraordinaria carga sarcástica que se esconde detrás de las referencias al pasado del ex presidente del PNV: “También habla alemán divinamente Javier Arzallus. Lo aprendió cuando creía más en Dios que en el Diablo, y cubría su estructura de rubio roble vasco con la zaína sotana de los viejos jesuitas” (2005b). Y menos dudas aún ofrece el sarcasmo que se esconde tras estas palabras en las que anima al terrorista José Ignacio de Juana Chaos a que realice una huelga de hambre de cien días:

“Otegui, por ejemplo, siempre ha finalizado sus períodos de inanición más gordo que al iniciarlos. Alguno de los grandes cocineros vascos le mandaban cestas repletas de delicias culinarias. Y así salía, más fuerte que Manolo el del Bombo. De ahí que me atreva a proponerle a De Juana Chaos una huelga de hambre de cien días. Ésa sí es una huelga de hambre verdadera y decente. Millones y millones de españoles le quedaríamos muy agradecidos por su determinación" (2006).

\subsection{Las situaciones cómicas}

Otro de los recursos que Ussía emplea más a menudo para reforzar sus críticas hacia el nacionalismo es la creación de historias y situaciones ficticias y de carácter cómico que se desarrollan en entornos relacionados con la cultura vasca. De esta manera pretende ridiculizar el ansia que, desde la perspectiva de Ussía, tiene el nacionalismo de enarbolar la cultura de esta región como un arma para defender y justificar sus ideas políticas. En algunas ocasiones el propio columnista se convierte incluso en un personaje directo de la escena en cuestión. Según apunta Morales, de esta manera el autor demuestra que "es capaz de reírse de sí mismo, de revelar sus propios defectos y debilidades; es decir de participar en la ridiculización de lo cómico" (1999: 102). Esta técnica puede advertirse en la siguiente escena en la que Ussía recrea una situación con él mismo como protagonista:

“Cuando niño, en la Parte Vieja de San Sebastián, junto al muelle, regentaba un negocio de ultramarinos un mercader arisco con harta fama de nacionalista. Estaba en situación de cabreo permanente. Una mañana, me atreví a preguntarle por el precio de un cucurucho de aceitunas aliñadas. 'A duro, pues', me dijo. Se me antojó el precio altísimo, y escapóseme el comentario. ‘Qué caro!'. Ni se inmutó. 'No lleves, quédate con las ganas. Ya las comeré yo’. Muy probablemente, primo de Arzallus” (2008a).

En otras ocasiones son los propios representantes del nacionalismo vasco los actores del relato cómico. El objetivo de estas situaciones también es ridiculizar a aquellas personas que directa o indirectamente hayan 
expresado algún apoyo, por mínimo que sea, al nacionalismo, mediante la recreación de escenas irreales, pero siempre acompañadas de paisajes y costumbres vascas. Sirva como ejemplo este extracto en el que, al igual que en el anterior, Ussía critica el mal humor que, en su opinión, tienen los nacionalistas, poniendo a Arzallus de nuevo en el punto de mira de su burla:

"Paseaban Arzallus y su novia por los jardines de Alderdi-Eder en San Sebastián. A ella le entró la fogarada del amor y se atrevió a darle una ráfaga de beso en el moflete derecho. Él se sobresaltó. ‘¿Qué haces, mujer?'; 'Es que te quiero, Javiercho'; 'Pues ya te he dicho mil veces que no pienses en esas cosas” (2003c).

A veces el columnista crea un interlocutor ficticio, pero en clara alusión a algún personaje en concreto, como por ejemplo este relato extraído de la misma columna del ejemplo anterior, en el que desliza, mediante el empleo del sarcasmo, una cruel crítica contra Monseñor Setién:

"En la parroquia del Antiguo, en San Sebastián, confesaba un sacerdote muy nacionalista. Si el pecador era simpatizante del tinglado, la penitencia que imponía era mínima. Si se confesaba un 'maqueto', temblaba el quiosco. 'Padre, que se me ha ido la mano y he matado a un guardia civil'. 'Nada hijo, no hay que preocuparse. Eso es pecado venial. No mereces penitencia'. 'Padre, que se me ha ido la mano y le he tocado los pechos a mi novia'. '¿De dónde eres?'. 'Soy de Madrid'. ‘¿Y la novia?'. 'De San Sebastián'. 'Por deshonrar con tus manos sucias a una chica vasca de toda la vida, vas a rezar sesenta rosarios completos. Sinvergüenza' (2003c).

\subsection{El lenguaje coloquial}

Uno de los grandes maestros de la historia del columnismo, Manuel Alcántara, parafraseando a Gerardo Diego, asegura que un columnista es "un cantor de lo cotidiano y un salvador de instantes" y la columna "una conversación en escrito con el lector" (2007: 21). Efectivamente, fruto de la libertad de que disfruta el columnista para plasmar sus pensamientos, este hace uso en muchas ocasiones de expresiones y palabras propias del lenguaje coloquial, algunas con una intencionalidad claramente burlona. Ussía desciende así desde su atalaya como escritor omnisciente e iguala su forma de expresarse a la del lector común y, de esta manera, le facilita el proceso de comprensión y asimilación de su argumentación.

En esta línea, Ussía emplea continuamente expresiones vulgares dentro de sus propias argumentaciones. Sirvan como ejemplo estos dos extractos, ambos acerca del PNV. En el primero ridiculiza las relaciones entre este partido y el Sin Fein irlandés: "Se les hace el culo agua con Gerry Adams. El líder del Sin Fein se ha convertido en el embajador del nacionalismo vasco en el mundo” (1998). En el segundo desliza una pequeña confesión al lector sobre su predisposición para escribir sobre el nacionalismo: 
"Nada me aburre más que escribir de los nacionalistas vascos. En ocasiones resulta imposible librarse del tostón, por motivos de actualidad y escándalo. No es responsable huir del tedio en beneficio del bienestar personal. Algunos lectores me lo sugieren. 'Deje usted de escribir de los nacionalistas, que es un coñazo" (2003b).

\subsection{El insulto jocoso}

En línea con el uso de expresiones vulgares, Ussía hace reiteradamente uso de insultos para descalificar a los representantes políticos con un mayor apego a las tesis nacionalistas y a los terroristas. No pretendemos ahondar en esta cuestión, pues estaríamos desviándonos del tema planteado inicialmente, pero sí queremos analizar un tipo de descalificaciones en las que el autor busca claramente la ridiculización del personaje mediante la burla. Y es que, además del insulto de carácter más agresivo -también muy presente en la obra periodística de Ussía-, existen muchos calificativos con un tinte más jocoso, otros suavemente ofensivos, e, incluso, algunos de carácter cariñoso (Luque et al., 1997: 17). En el siguiente ejemplo se puede apreciar perfectamente cómo tras una ristra de calificativos muy ofensivos hacia los terroristas, Ussía finaliza con un insulto como "tonto" con el que no busca la injuria, sino la ridiculización: "Los terroristas, antes que asesinos, miserables, cobardes, fanáticos, perversos y aldeanos, son tontos” (2008c). Asimismo, se refiere a Juan José Ibarretxe como el "pelele de la imposibilidad" (2005a) o asegura que los futbolistas vascos que se negaban a jugar con la selección vasca si no era representando a Euskal Herria son "unos petardos como estudiantes y unos petardos como futbolistas" (2008b).

\subsection{La modificación del lenguaje}

Uno de los recursos humorísticos más comunes en el estilo de Ussía es la caricaturización del idioma vasco mediante la deformación de términos y la creación de nuevas palabras. Con esta técnica el autor no pretende ningunear esta lengua, sino atacar a los partidos nacionalistas pues, desde su perspectiva, estos han convertido el vascuence en un arma política. Es más, como ya hemos comprobado líneas atrás, Ussía siempre pretende transmitir su amor y respeto por los diferentes aspectos que conforman la cultura vasca, entre estos las raíces de su idioma:

"El vascuence o euskera no es un idioma específico y ordenado como tal. Lengua oral y no escrita hasta finales del siglo XVIII se divide en siete dialectos que rompen su unidad. [...] Para 'normalizarlo', los nacionalistas no han hecho otra cosa que españolizarlo al máximo, para así entenderse, y se han inventado el 'batua” (2004b).

La “eusquerización” burlona del castellano es una de las formas mediante las que Ussía consigue ese efecto de caricaturización. Para ello, hace uso de terminaciones típicas de la lengua vasca y crea expresiones como 
"almorranúas pikoak" para referirse a las hemorroides que, en su opinión, sufre el terrorista José Ignacio de Juana Chaos y gracias a las cuales pudo abandonar la prisión (2007) o le cambia el nombre a los dirigentes del PNV Xabier Arzallus y Juan José Ibarretxe por los de “Javiercho” y “Pelonchu” (2000). También introduce comienzos de palabras típicamente vascos y transforma términos como "sondeo" en "txondeo” (2000).

Queda patente tras estos ejemplos que, según apunta Pato, modificaciones del lenguaje de estas características no responden a una necesidad racional, sino afectiva y expresiva que se producen "cuando se quiere plasmar esa necesidad en palabras y frases que sean capaces de provocar efectos cómico-lúdicos, y un contenido afectivo-conceptual integrado por las reacciones del hablante-escritor" (2007).

En otras ocasiones Ussía también "adapta" otros idiomas o dialectos mediante la reproducción literal de algunos rasgos fonéticos propios de la lengua o dialecto en cuestión. Por ejemplo, el francés para criticar a la organización del Tour de Francia:

“Si tuotes les organizations internationales, si les Etats Unis de L’Amerique, si la Justice espagnole et europeéne ha consideré a Batasuna comme group terroriste, ¿ipourquoi Le Tour de France signe avec les asassins et ses complices un acord de colaboration? ¿Pourquoi?” (2003a).

\subsection{Las comparaciones caricaturescas}

Ussía tiende a ridiculizar las pretensiones nacionalistas mediante su comparación de una forma jocosa con otras similares, pero aplicadas a otros países o regiones de menor tamaño o importancia. Veamos dos ejemplos separados por treinta y dos años en el tiempo. En el primero, publicado en 1977, confecciona una concatenación de versos para pedir públicamente que el madrileño barrio de Vallecas se constituyese como una nueva Comunidad Autónoma: “¡Pido Fueros como los de Navarra / y enseñanza en la escuela del idioma / de Vallecas autóctono, el Macarra. / Las naciones de España, día a día, / en esta libertad de paz y flores / encuentran su preciada autonomía." (1977). En el segundo, publicado en 2009, compara las ansias nacionalistas de vascos y catalanes con las de la tribu chilena mapuche y la argelina amazic: "Al fin, los nacionalistas catalanes, mapuches, vascos y amazic podrán aunar sus esfuerzos para alcanzar la plena soberanía, que en el caso de los mapuches y los argelinos amazic, se está retrasando más de lo conveniente” (2009a).

Ussía también compara en ocasiones a los políticos con objetos inanimados o con personajes de ficción con el fin de provocar la carcajada en el lector. En este caso el efecto satírico-burlesco, subraya Morales, se produce por tres razones fundamentales: “La oposición entre lo 'material' y 'humano', la plasticidad que apela a la imaginación y fantasía del lector, y el carácter sintético de las comparaciones” (1999: 256). 
Esta técnica ha estado presente a lo largo de toda su carrera como columnista. Así, asegura que el ex coordinador general de Ezker Batua Javier Madrazo tiene "rostro de manzana reineta" (2001a) o que Xabier Arzallus guarda muchas similitudes con el abuelo de Heidi, pues está “chocho con el nieto" (2002). En este último ejemplo, además de la comparación caricaturesca, confluyen al mismo tiempo la reproducción de expresiones coloquiales y la recreación de escenas ficticias:

“Dicen que Ibarreche llama a Arzallus por teléfono y sólo oye en el auricular frases como ésta: 'Pocholo, prrrrr, muá muá'. Que Anasagasti fue a visitarlo para consultar su intervención en el Congreso de los Diputados, y se encontró con Arzallus dando saltos en cuclillas en torno a una cuna y con un pirulo en la cabeza" (2002).

\subsection{Las "buenas maneras"}

Ya hemos avanzado en la reseña biográfica que Ussía ha prestado mucha atención en su obra al análisis cómico y burlesco de las normas de protocolo y educación que, en su opinión, se deben adoptar en acontecimientos y reuniones sociales. Además de los Tratados de las buenas maneras, fruto de sus escritos en $A b c$, cabe recordar la figura del marqués de Sotoancho, al que ya aludíamos líneas atrás, un personaje ficticio creado por el propio Ussía, en parte a semejanza de sí mismo, que se mueve dentro de un círculo selecto y aristocrático y en el que pueden presentarse este tipo de situaciones. En sus columnas sobre el País Vasco en muchas ocasiones recrea escenarios de estas características que le sirven para explicar el porqué de su amplio conocimiento de la sociedad y la cultura de la región:

“Sin 'puestas de largo' la sociedad se ha horterizado. Esta 'jet set' de chicha y nabo, marbellense insoportable, lo ha echado todo a rodar. Una 'puesta de largo' estival, en villa cimera de Igueldo, dominando la iluminada bahía donostiarra, ha marcado a toda una generación. La mía. La de los últimos beodos de la decencia ilustrada” (1984b).

Ussía muchas veces ridiculiza a los representantes del nacionalismo vasco o a los terroristas, lanzando una comparación entre pequeños detalles de la forma de actuar de estos y cómo deberían de haberlo hecho desde una conducta de carácter más protocolaria. Por ejemplo, critica las ansias nacionalistas de Arzallus por el hecho de que este haya participado en un mitin con zapatillas de deporte:

"Ha asistido al Alderdi Eguna vestido de propietario de chalé de la sierra de la década de los sesenta. De madrileño de barbacoa el sábado al mediodía. A este paso, en lugar de la autodeterminación, va a terminar pidiendo una bolsa de carbón vegetal. [...]. Así no se puede autodeterminar nadie, hortera, pedazo de hortera" (2001b).

Asimismo, se lamenta de que unos representantes de Herri Batasuna se hayan reunido en el aristocrático y selecto hotel Ritz de Madrid: "Me ha atormentado la imagen burda de esos mamarrachos de Hitler-Batasuna 
desayunando en sus recintos, mamando de sus cremas, manchando con sus hocicos los nobles cantos de sus tazas" (1984a).

\section{Conclusión}

La amenidad y la chispa de los recursos humorísticos en la obra periodística de Alfonso Ussía, así como la consiguiente intencionalidad que se esconde tras ellos, cobran toda su forma en aquellos escritos en los que el autor trata alguna cuestión relacionada con la política vasca. Fruto de su "lucha" constante contra el nacionalismo y, sobre todo, el terrorismo, Ussía se ha construido una imagen pública de sí mismo, por un lado, de estandarte de apoyo absoluto e incondicional hacia aquellas personas que defienden públicamente la unidad de España y, sobre todo, que combaten frontalmente el terrorismo; por otro, de oposición radical a los representantes del nacionalismo y, principalmente a aquellos personajes públicos que, desde su perspectiva, no se enfrentan de "tú a tú" al terrorismo o que, incluso, indirectamente lo apoyan. En términos aristotélicos, este apoyo o rechazo de Ussía representa el patetismo en el discurso, una técnica a la que el columnista acude, mediante diversos recursos como los humorísticos, para desarrollar sus argumentaciones y crear así su propio ethos de cara al lector.

López Pan destaca la importancia de los valores morales dentro de esa influencia que tiene el patetismo en el discurso como elemento configurador del ethos: "Las reacciones ante los acontecimientos o sucesos que se comentan o juzgan se añaden como una variable más a la hora de consolidar una determinada impresión moral del orador en el ánimo de los oyentes" (1996: 68). Efectivamente, Ussía, explícita o implícitamente, muestra un apoyo o un rechazo de carácter moral a los protagonistas de la actualidad, y la intensidad de su burla y sarcasmo hacia ellos es proporcional al grado de vinculación de sus ideas políticas con las de dichos personajes. Por esta circunstancia, en un extremo se encuentran aquellos individuos que llevan sus tesis nacionalistas hasta la radicalidad (los terroristas y aquellas personas que, desde la óptica de Ussía, lo apoyan) y, en el otro, las víctimas de los asesinos, hacia las cuales el autor no desliza ninguna broma en sus columnas, solo palabras de alabanza y respeto. En medio de ambos polos se encuentran todo tipo de personajes, generalmente políticos, que "sufrirán" el látigo satírico de Ussía en función de la actitud pública que hayan mostrado respecto a las tesis nacionalistas y al terrorismo.

Ussía emplea un extraordinario elenco de técnicas humorísticas para analizar la política vasca de una forma ininterrumpida desde hace más de treinta años y ello le ha servido para crearse una imagen de sí mismo de estilete del nacionalismo y el terrorismo. Además, para vertebrar su afinada burla, comparte con el lector una infinidad de confesiones personales sobre su vinculación familiar con el País Vasco y su pasión hacia 
esta tierra, lo cual contribuye también a perfilar ese ethos que Ussía se ha sabido construir a través de su obra periodística.

\section{Referencias bibliográficas}

Busutil, Guillermo (2007): Entrevista a Manuel Alcántara, Mercurio. Panorama de libros, Sevilla, Fundación José Manuel Lara, No 95, de noviembre de 2007.

Deweese, Pamela (2003): "La ironía: el arte de la interpretación", en Actas del X Simposio Internacional sobre narrativa hispánica contemporánea. La ironía en la narrativa hispánica contemporánea (Puerto de Santa María, Cádiz, noviembre de 2002), 2003: Fundación Luis Goytisolo.

Equipo de sincolumna.com (2006): Entrevista a Vicente Molina Foix. En sincolumna.com, 13 de diciembre. Disponible en: http://www.sincolumna.com/con_columna/molinafoix/cuestionario.html [Consultado el 03.11.2009]

Fernández Flórez, Wenceslao (1945): El humor en la literatura española. Discurso leído ante la Real Academia Española, 14 de mayo de 1945, Madrid: Imprenta Sáez.

Forneas, María Celia (2003): “La columna periodística: algunas ideas” en Estudios sobre el mensaje periodístico, № 9. Madrid, Servicio de Publicaciones de la Universidad Complutense.

Grijelmo, Álex (2003): El estilo del periodista (undécima edición), Madrid: Taurus.

Grohmann, Alexis (2006): “El columnismo de escritores españoles (1975-2005): hacia un nuevo género literario”, en Grohmann, A.; Steenmeijer, M (eds.): columnismo de escritores españoles (1975-2005), Madrid:Verbum.

López Hidalgo, Antonio (1996): Las columnas del periódico, Madrid: Ediciones Libertarias/Prodhufi.

López Pan, Fernando (1996): La columna periodística. Teoría y práctica, Pamplona: Ediciones Universidad de Navarra (Eunsa).

- (2008): "La columna como paradigna de los géneros", en León Gross, Teodoro (dir.) y Gómez Calderón, Bernardo (ed.): El artículo literario: Manuel Alcántara, Málaga: Servicio de Publicaciones de la Universidad de Málaga / Fundación Manuel Alcántara.

Luque, Juan de Dios, Pamies, Antonio y Manjón, Francisco José (1997): El arte del insulto. Estudio lexicográfico, Barcelona: Península.

Mainar, Rafael (2005): El arte del periodista (1ª edición de 1906), Fuenlabrada (Madrid): Destino.

Morales Castillo, Fabiola (1999): Recursos de humor en el periodismo de opinión, Universidad de Piura.

Muñoz Molina, Antonio (2007): “Literaturas de periódico”, Mercurio. Panorama de libros, Sevilla, Fundación José Manuel Lara, n. ${ }^{\circ}$ 95, de noviembre de 2007. 
Pato, Enrique (2007): “La función lúdica del lenguaje y la creación de palabras por medio de sufijos y prefijos”, en Tinkuy. Boletín de investigación y debate, № 4, Montreal, Universidad de Montreal. Disponible en: http://www.littlm.umontreal.ca/recherche/publications/Tinkuy4.pdf\#page $=109$

Real Academia Española, RAE (1992): Diccionario de la lengua española. Vigésima primera edición, Madrid: Espasa-Calpe. Turpin, Enrique (2003): "La ironía, acorde y compás de la escritura", en Actas del X Simposio Internacional sobre narrativa hispánica contemporánea. La ironía en la narrativa hispánica contemporánea (Puerto de Santa María, Cádiz, noviembre de 2002), Puerto de Santa María (Cádiz): Fundación Luis Goytisolo.

Ussía, Alfonso (1970): "Poema del viejo atardecer”, Litoral, 7 de julio.

- (1977): “Poema a ICONA norte”, Sábado Gráfico, 24 de diciembre.

- (1983): “La última vez”, Las Provincias, 27 de noviembre.

- (1984a): “El Ritz”, Diario 16, 19 de enero.

- (1984b): "Puestas de largo", Diario 16, 16 de noviembre.

- (1985a): “El nuevo 'extranjero”, Diario 16, 8 de abril.

- (1985b): “Lienzos y condecoraciones”, Diario 16, 19 de octubre.

- (1986): “Gentuza”, Las Provincias, 29 de octubre.

- (1991): "El endrinal”, $A b c, 30$ de enero.

- (1998): "Paletos", $A b c, 7$ de octubre.

- (2000): "El txondeo", $A b c, 21$ de abril.

- (2001a): "El fusilado", $A b c, 27$ de abril.

- (2001b): "Las zapas", $A b c, 2$ de octubre.

- (2002): "El abuelo de Heidi", $A b c, 6$ de septiembre.

- (2003a): "Le Tour", Abc, 6 de julio.

- (2003b): “Tostón”, Abc, 21 de enero.

- (2003c): "El enfado", $A b c, 19$ de noviembre.

- (2004a): “Al obispo Uriarte”, La Razón, 4 de junio.

- (2004b): “Moratinos y Babel”, La Razón, 17 de septiembre.

- (2004c): “Ni yo”, La Razón, 28 de diciembre. 
- (2005a): “Las cejas”, La Razón, 4 de febrero.

- (2005b): “Thank you”, La Razón, 11 de diciembre.

- (2006): “Mejor cien”, La Razón, 17 de octubre.

- (2007): “Ipurdi' picante”, La Razón, 19 de mayo.

- (2008a): "El cabestro”, La Razón, 28 de marzo.

- (2008b): “Petardos”, La Razón, 15 de noviembre.

- (2008c): “Encefalograma plano", La Razón, 10 de diciembre.

- (2009a): "Mapuches", La Razón, 17 de enero.

- (2009b): “Gorbeako Gurutzea”, La Razón, 28 de junio. 